\title{
Recognizing and Responding to the Health Disparities of People with Disabilities
}

\author{
Charles E. Drum, Gloria Krahn, Carla Culley, and Laura Hammond
}

Oregon Health \& Science University

\begin{abstract}
Health status is critically important to experiencing quality of life, self-sufficiency, and full participation in society. For the 54 million Americans with disabilities, maintaining health and wellness is especially important to reduce the impact of impairment on functioning in these critical life areas. Yet, people with disabilities may be the largest underserved subpopulation demonstrating health status disparities that stem from preventable secondary conditions. Healthy People 2010, the nation's blueprint for improved health, addresses this problem in its objectives. In 2002 and 2005, the U.S. Surgeon General asked for public health efforts to improve the health and wellness of persons with disabilities. This article examines the concepts of health and wellness, summarizes currently available information documenting disparities in health for people with disabilities, and provides a framework for policy recommendations to reduce health disparities among people with disabilities.
\end{abstract}

(C) 2005 Californian Journal of Health Promotion. All rights reserved.

Keywords: health disparities, disability, health and wellness

\section{Introduction}

For the approximately 54 million Americans with disabilities (McNeil, 2001), maintaining health, wellness, and minimizing secondary conditions are important in reducing the impact of impairment on functioning and participation. Yet, people with disabilities may be the largest underserved population that demonstrates evidence of health disparities. The concept of having a disability and being healthy is relatively new (Krahn, 2003). Until recently, disability was presumed equivalent to illness, and it elicited all the associations of dependence, lack of productivity, and physical and sexual inactivity that are incumbent to the notion of illness (DeJong, 1994; Nosek, 1996). As demonstrated in several Surgeon General reports -- Closing the Gap: A National Blueprint for Improving the Health of Individuals with Mental Retardation (USDHHS, 2002) and The Surgeon General's Call to Action To Improve the Health and Wellness of Persons with Disabilities (USDHHS, 2005) -- and Healthy People 2010 (USDHHS, 2001), there is an increasing public health commitment to addressing the health and wellness of persons with disabilities.
The goal of this article is to provide an overview of health disparities experienced by people with disabilities. The article describes:

1. Concepts of health and wellness;

2. Different disability models;

3. Disability surveillance activities and prevalence rates;

4. Public health and disability research;

5. Disparities experienced by people with disabilities; and

6. Recommendations for addressing health disparities.

\section{Defining Health and Wellness}

"Health and wellness" involve physical, emotional, social, spiritual, and other factors that enable individuals to maximize their potential and fully participate in their community. For persons with disabilities, as with the rest of the population, health status is a dynamic process that changes over time. Rather than thinking of "health" and "illness" as opposite and binary categories, it is useful to consider a continuum of health and illness along which individuals move, enjoying relatively better health at some times in their lives than others. A person's 
unique circumstances and a wide variety of contributors define his or her "optimal health" (Kailes, 2004).

\section{Contributors to Health}

In order to achieve "optimal health," it is important to examine what factors contribute to health status. Determinants of population health outcomes have been grouped into five categories: genetic predispositions, environmental conditions, social circumstances, behavioral patterns, and medical care access (McGinnis, Williams-Russo, \& Knickman, 2002). While the determinants of genetics, environmental exposures, and social circumstances are less easily modified, individual behaviors and access to medical care are more amenable to intervention. The Institute of Medicine has identified a number of behavioral, social, and clinical interventions that effectively address health promotion behaviors (Smedley \& Syme, 2000). Policy and systemic changes can be instituted that increase medical care access, thereby contributing to health and wellness. Figure 1 depicts the contributors to differential health status of persons with disabilities relative to the general population.

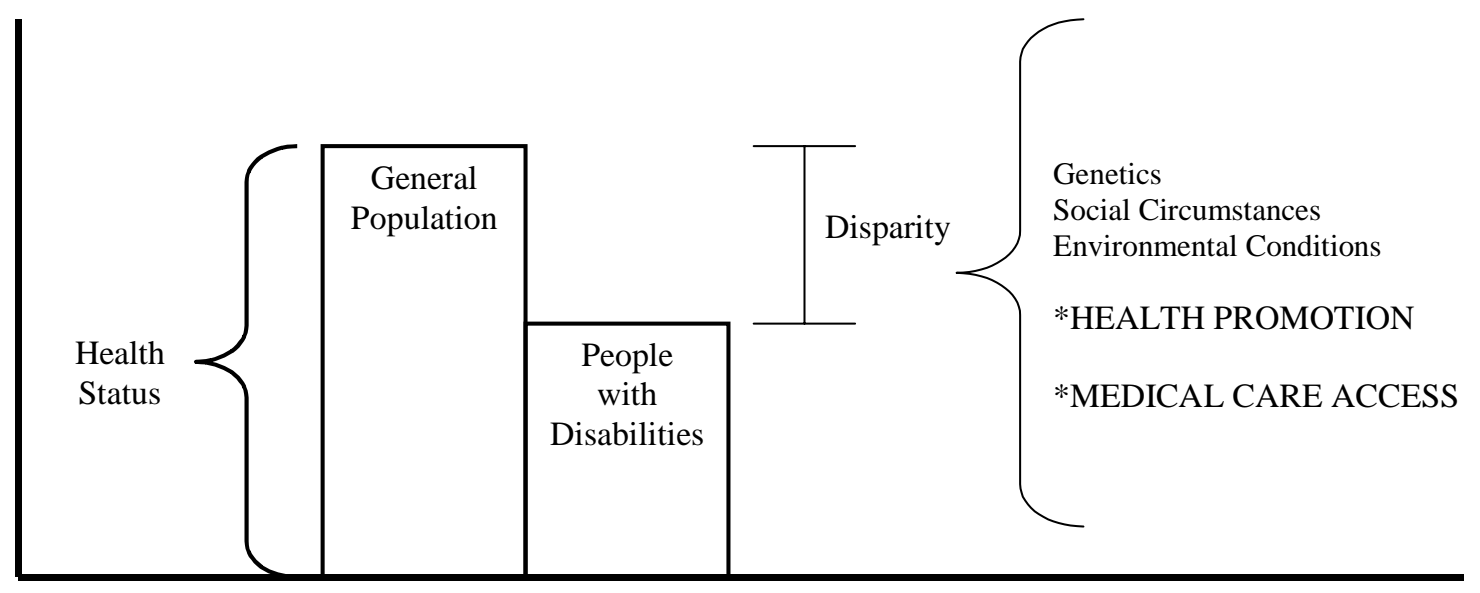

Figure 1

Contributors to Health Disparities Among Persons with Disabilities

Compared to the General Population

\section{Defining Disability}

Disability often reflects the zeitgeist of a particular era: what is considered a disability at one point may change through formal and informal social or political processes. When contemporary public health considers disability, most of its perspectives derive from the medical model of disability, although functional and social models are increasingly present. Each of these approaches to disability is described below.

Under the medical model, disability derives from disease, trauma, or health impairments or deficits located within an individual that can be cured or ameliorated through a particular treatment or intervention (Bickenbach, Chatterji, Badley \& Ustun, 1999; Johnston, 1996; 
Llewellan \& Hogan, 2000; Rioux, 1999). Examples of disability from a medical model perspective include consideration of diagnostic categories such as spinal cord injury, multiple sclerosis, and traumatic brain injury. The medical model is based in the etiology of the condition. The functional model to disability differs from the medical model in that, while the source of the disability is individualistic and linked to medical, physiological, or cognitive impairments or deficits, the expression of disability is the inability to perform a number of functional activities regardless of etiology. For example, someone has a disability under the functional model if, due to an underlying impairment or condition, they are unable to perform vital physical or mental activities such as breathing, moving, living independently, or working (Bickenbach, et al., 1999; Rioux, 1999).
A number of social models of disability have been developed as an alternative to medical and functional models. Social models to disability typically shift disability from considering deficits or impairments within an individual to examining the barriers people (with underlying impairments or conditions) face when interacting with the environment (Drum, 1998; Humphrey, 2000). Social models argue that disability is a consequence of social (dis)organization that creates or results in inaccessible environments (see Figure 2). For example, under the social model, a woman with quadriplegia who wants to work experiences a disability when she is excluded from a work site due to an inaccessible entrance.

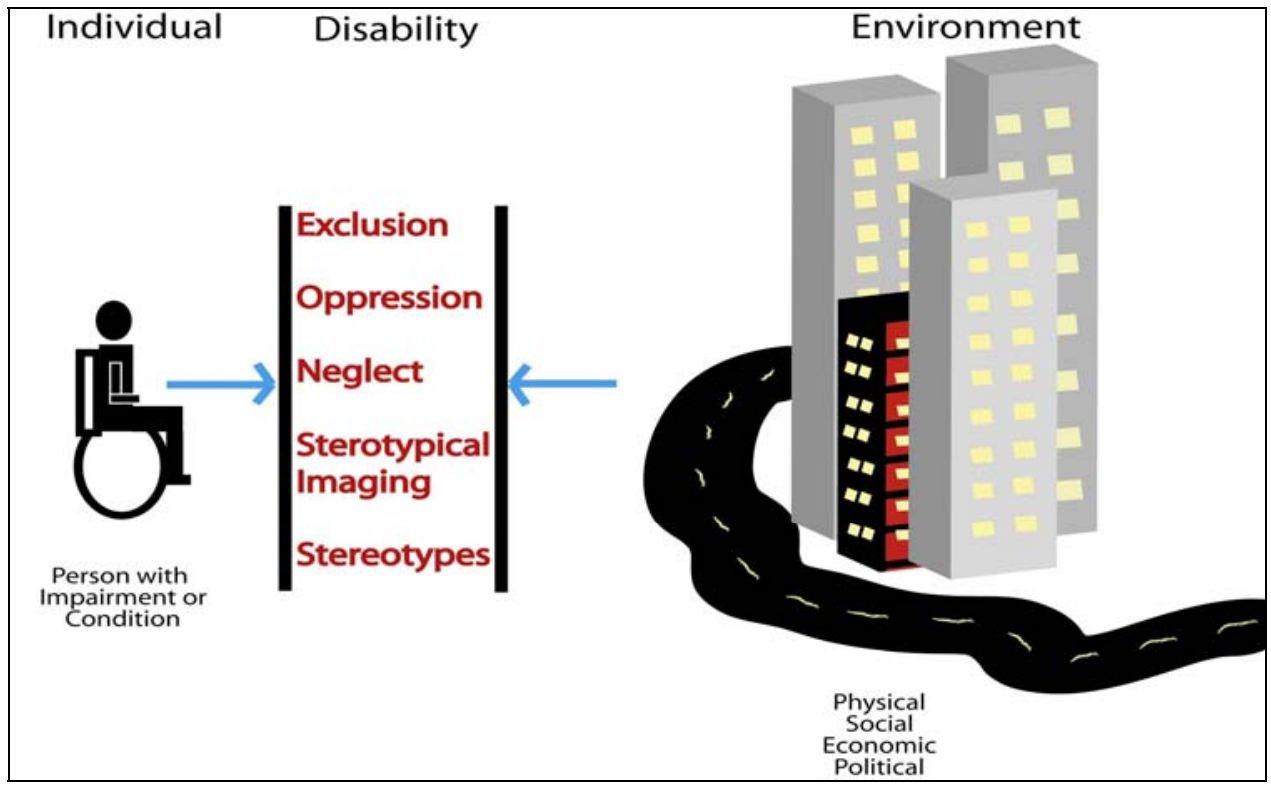

Figure 2

Graphic Representation of the Social Model of Disability (Drum, 2004)

\section{Federal Approaches to Disability}

United States legislation and policy has created upwards of sixty-seven definitions of "disability," including variations in the term such as "handicap," "disabled person," and “individual with a disability.” There are overlaps among definitions, and some legislation uses more than one definition. For example, the Americans with Disabilities Act (ADA) (ADA, 1990) recognizes multiple dimensions of 
disability including pathology/impairment and functional and social role limitations. Under the ADA, a person with a disability is defined as an individual who: (a) has a physical or mental impairment that substantially limits at least one "major life activity," or (b) has a record of such an impairment, or (c) is regarded as having such an impairment (29 U.S.C. 705). Examples of "major life activities" range from breathing, caring for one's self, walking, seeing, hearing, and speaking to learning, working, and participating in daily community living.

Functional approaches to disability are present in a number of programs in the United States. For example, Section 223(d)(1) of the Social Security Act defines disability as the "inability to engage in any substantial gainful activity by reason of any medically determinable physical or mental impairment which can be expected to result in death or which has lasted or can be expected to last for a continuous period of not less than 12 months.” The Act makes clear that it is the inability to engage in employment that creates a disability, not the presence of medically determinable physical or mental impairments.

On the other hand, using a medical model to establish eligibility for governmental services is usually considered efficient. In general, categorical assessments can be reproduced consistently and fairly simply in determining program or entitlement eligibility (Drum, 2004). One example of a program using a medical model is state Vocational Rehabilitation programs for people who are blind. The programs provide assistance in obtaining and retaining a job. Eligibility for these services is limited to people who are "legally blind." Legal blindness refers to clinically measured visual acuity with correction that is $20 / 200$ or less in the better eye, or where the visual field has contracted so that the widest diameter is 20 degrees or less (American Federation for the Blind, n.d.).

\section{Integrated Approaches to Disability}

A number of contemporary approaches combine medical, functional, and social approaches to disability. Consistent with this viewpoint, the Institute of Medicine disseminated its 1991 report, Disability in America, incorporating the terminology and well-regarded framework for understanding disability devised by sociologist Saad Nagi in the 1950s. In this report, disability is described as a process rather than as a static condition (Pope \& Tarlov, 1991). The disabling process is conceptualized as consisting of four major dimensions: pathophysiology ("active pathology” for Nagi), impairment, functional limitation, and disability.

The National Center for Medical Rehabilitation Research (NCMRR) further expanded the notion of the disabling process by inserting an additional dimension of societal limitations. These are defined as a "restriction, attributable to social policy or barriers (structural or attitudinal), which limits fulfillment of roles or denies access to services and opportunities that are associated with full participation in society” (USDHHS, 1993).

The modified Nagi model, displayed schematically in Table 1 , is a disabling process model that illustrates the convergence of underlying intra personal factors with extrapersonal factors of the physical, social, and cultural environment. The added dimension of societal limitations focuses attention on environmental barriers that contribute to the disabling process. The modified Nagi model illustrates the importance of the interaction effects between individual capacities and flexibility of the environment to express those capacities. The ability to assess functional status in a particular environmental context is essential for promoting the health and well-being of people. 
Table 1

NCMRR Modification of the Nagi Model

\begin{tabular}{|c|c|c|c|c|}
\hline $\begin{array}{c}\text { Active } \\
\text { Pathology }\end{array}$ & Impairment & $\begin{array}{l}\text { Functional } \\
\text { Limitation } \\
\end{array}$ & Disability & $\begin{array}{c}\text { Societal } \\
\text { Limitation }\end{array}$ \\
\hline $\begin{array}{l}\text { Interruption or } \\
\text { interference with } \\
\text { normal processes } \\
\text { and effort of the } \\
\text { organism to } \\
\text { regain normal } \\
\text { state; indicators } \\
\text { are symptoms } \\
\text { and signs found } \\
\text { in attributes of } \\
\text { the individual. }\end{array}$ & $\begin{array}{l}\text { Anatomical, } \\
\text { physiological, } \\
\text { mental or emotion } \\
\text { abnormalities or } \\
\text { loss; indicators } \\
\text { are symptoms and } \\
\text { signs found in } \\
\text { attributes of the } \\
\text { individual. }\end{array}$ & $\begin{array}{l}\text { Limitation in } \\
\text { performance at the } \\
\text { level of the whole } \\
\text { person in activities } \\
\text { such as walking, } \\
\text { climbing, reaching, } \\
\text { and hearing; } \\
\text { indicators can be } \\
\text { grouped into } \\
\text { categories such as } \\
\text { physical, mental, } \\
\text { sensory, and } \\
\text { communication }\end{array}$ & $\begin{array}{l}\text { Limitation in } \\
\text { performance of } \\
\text { socially defined } \\
\text { roles and tasks } \\
\text { related to family, } \\
\text { work, community, } \\
\text { school, recreation, } \\
\text { and self-care } \\
\text { within a } \\
\text { sociocultural and } \\
\text { physical } \\
\text { environment. }\end{array}$ & $\begin{array}{l}\text { Restriction } \\
\text { attributable to } \\
\text { social policy or } \\
\text { barriers (structural } \\
\text { or attitudinal), } \\
\text { which limits } \\
\text { fulfillment of roles } \\
\text { or denies access to } \\
\text { services and } \\
\text { opportunities that } \\
\text { are associated with } \\
\text { full participation in } \\
\text { society. }\end{array}$ \\
\hline
\end{tabular}

\section{International Classification of Functioning, Disability and Health (ICF)}

A related major conceptual model developed to guide research and to assess functional status need is the International Classification of Functioning, Disability and Health. Originally created through the support of the World Health Organization (WHO) as the International Classification of Impairments, Disabilities, and Handicaps (ICIDH) (WHO, 1980), the ICF is an assessment tool that captures a broad array of information relating to health and functioning (WHO, 2001).

The ICF describes health and health-related conditions in terms of an interaction between functioning, disability, and contextual factors (see Figure 3). Functioning and disability are structured around two broad components: 1) body functions and structures and 2) activities and participation. The first set of components focuses on assessing body functions and body structure. The second set focuses on assessing capacity and performance. Since individual functioning and activity participation occur within a context, the ICF includes the contextual factors of environmental facilitators and barriers as well as personal factors (i.e., severity) (WHO,
2001). The result is an assessment that views functioning and disability as the complex interaction between individual health and contextual and personal factors. The recognition of the role of the environment on health and well-being for people living with a disability is a critical element for public health interventions. Ideally, use of the ICF will allow public health and health practitioners to identify which components of an individual's functioning are being addressed by a particular intervention (Lollar, 2001; 2002).

\section{Disability Surveys \& Prevalence Estimates}

A number of national surveys have been or are conducted by US federal agencies, including the US Bureau of the Census and the Centers for Disease Control and Prevention. Although population estimates are available through these efforts, their primary purposes are tied to program mandates and not necessarily to generating surveillance data. Moreover, different definitions of disability are often used in these efforts. For example, the US Bureau of the Census uses a combined medical and functional approach to disability in the decennial Census and in the American Community Survey. 


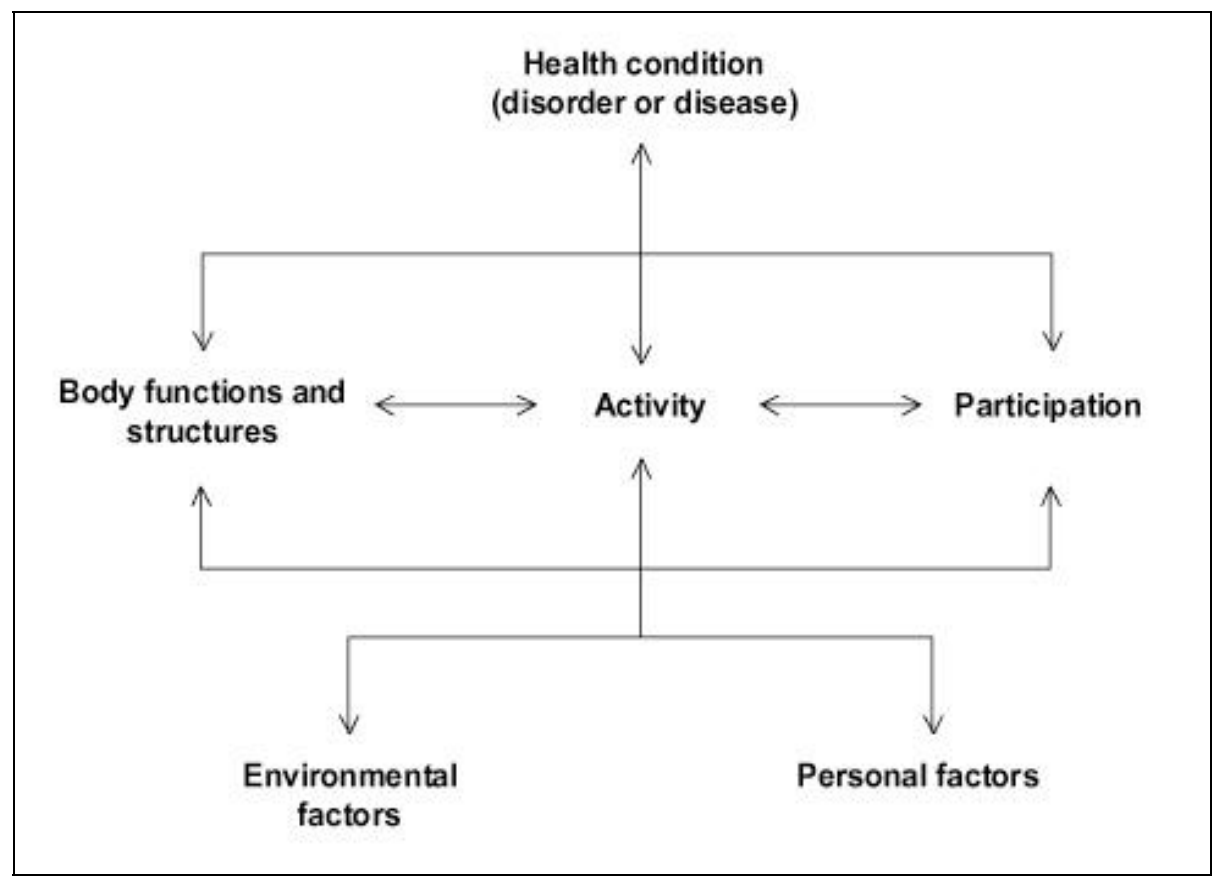

Figure 3

Interactions of ICF (WHO, 2001)

The Behavioral Risk Factor Surveillance System (BRFSS) is the nation's largest public health telephone survey. It is an annual survey conducted in every state and territory with the non-institutionalized population. Previously, a disability module or identifiers were implemented in a number of states on an intermittent basis. In 2001, two disability identifiers were added to the core modules of the BRFSS and, since 2003, basic data for this group are now available annually from every U.S. state and territory. In the BRFSS, disability is defined as being limited in any way in any activities because of physical, emotional, or mental problems, or as having any health problems that require the use of special equipment (Centers for Disease Control and Prevention [CDC], 2004).

The National Health Interview Survey (NHIS) is an annual nationwide survey of about 36,000 households in the U.S. conducted by the National Center for Health Statistics. It is a principal source of information on the health of the civilian non-institutionalized population. Disability identifiers were included in two years (1994/1995) of NHIS data collection and designated the NHIS-D. The NHIS-D was designed to collect data that can be used to understand disability, to develop public health policy, to produce simple prevalence estimates of selected health conditions, and to provide descriptive baseline statistics on the effects of disabilities. In the NHIS-D, disability is not limited to one definition of disability; rather, disability is viewed as the state of any short-term or long-term reduction in the ability to perform regular activities, resulting from either acute or chronic conditions (CDC, 2004).

The American Community Survey, first implemented in 2003, is an annual survey intended to displace the long-form version of the decennial Census. In these two Census Bureau surveys, disability is defined as a long-lasting condition such as blindness, deafness, or a severe vision or hearing impairment or a substantial limitation in basic physical activities 
such as walking, climbing stairs, teaching, lifting, or carrying. Severity of disability is determined through questions assessing the person's capacity to: 1) learn, remember, or concentrate; 2) dress, bathe, get around inside the home; 3) go outside the home to shop or visit the doctor's office; or 4) work at a job or business (USCB, 2005).

Another Census activity is the Survey of Income and Program Participation or SIPP. The SIPP is a continuing survey with monthly interviews of a multistage-stratified sample of the U.S. civilian non-institutionalized population. The purpose of SIPP is to collect income, labor force information, program participation and eligibility data, and general demographic characteristics to measure the effectiveness of existing federal, state, and local programs; to estimate future costs and coverage for government programs, such as food stamps; and to provide improved statistics on the distribution of income in the country. Under the SIPP, disability is defined as meeting one or more of the following criteria: 1) using a wheel chair, cane, crutch, or walker; 2) having difficulties performing functional activities; 3) having difficulties performing activities of daily living;
4) having difficulties performing instrumental activities of daily living; 5) having one or more specific mental or emotional conditions, or mental or emotional conditions that affect everyday living; 6) or having a condition that limits the ability to work around the house or at a job or business (USCB, 2004).

\section{Prevalence Rates of Disability}

Prevalence rates drawn from these surveys generate varying populations estimates owing to the use of varying definitions of disability and differences in design and data collection methods. Table 2 provides prevalence rates obtained from the five national surveys among males and females. Because of the higher rates of disability among older populations, the table is limited to prevalence rates among males and females with disabilities under the age of 65 . Data are drawn from different years because most of the surveys are not conducted annually and age ranges in the table differ slightly based on availability of data. The Census data are from 2000, the ACS from 2003, the SIPP from 2002, the NHIS-D from 1994, and the BRFSS from 2003. Given the limitations in the data, comparisons among the prevalence rates should be made conservatively.

Table 2

Prevalence Rates Among People with Disabilities in the US

\begin{tabular}{|c|c|c|c|c|c|c|c|c|c|}
\hline \multicolumn{2}{|c|}{ Census* } & \multicolumn{2}{c|}{ ACS** } & \multicolumn{2}{c|}{ SIPP*** } & \multicolumn{2}{c|}{ NHIS-D*** } & \multicolumn{2}{c|}{ BRFSS*** $^{* *}$} \\
\hline Males & Females & Males & Females & Males & Females & Males & Females & Males & Females \\
\hline 19.6 & 17.6 & 13.5 & 13.5 & 14.8 & 20.1 & 12.4 & 12.8 & 15 & 16.7 \\
\hline
\end{tabular}

* Ages 16-64 , **Ages 21-64, ***Ages 18-64

\section{Public Health and Disability}

The field of public health has evolved from its historical focus on fundamental issues of sanitation, water quality, and infectious disease control to a broader perspective that addresses chronic illness and lifestyle behaviors. This evolution is based both on successful eradication or control of many infectious diseases, as well as an increasing awareness of the complex social, political, economic, geographic, demographic, and physiologic factors that affect health. The field of public health has also made significant changes in how it views disability. Traditionally, when disability was included in public health, it was with a focus on primary prevention of disabling conditions (i.e., prevention of injuries and birth defects). A growing number of contemporary public health efforts include disability surveillance and support for research on health promotion activities for people with disabilities. 


\section{Disability \& Public Health Research}

During the past 30 years, the conceptualizations of "disability," "health and wellness," and the role of the "environment" in the disabling process have changed dramatically (Krahn, 2003). In the mid-1980's, national policymaker's focus was on the primary prevention of disabilities began to be extended to the prevention of "secondary disabilities" (Marge, 1988). Subsequently transformed into "secondary conditions," this concept highlights the increased risk that people with a primary disabling condition experience for additional health (and social) conditions that occur after their primary condition and result in poorer health. Secondary conditions are often regarded as substantially responsible for the health status differences that are observed between people with and without disabilities (Seekins, Clay, \& Ravesloot, 1994; Wilber, Mitra, Walker, Allen, Meyers, \& Tupper, 2003). Secondary conditions are defined as preventable health conditions by some authors (Simeonsson \& Leskinen, 1999) but not others (Campbell, Sheets, \& Strong, 1999).

Efforts at measuring and preventing secondary conditions date back to the work of Seekins in the early 1990s. Since then, numerous researchers have reported on the increased prevalence of particular physical (e.g., pressure sores, diabetes), mental (e.g., depression, anxiety) and social (e.g., social isolation, unemployment) conditions experienced by persons with specific diagnostic conditions (e.g., cerebral palsy, spinal cord injury), who selfidentify with a disability (e.g., Kinne, Patrick, \& Doyle, 2004; McDermott \& Platt, 2004; Turk, 2004; Wilber et al., 2003).

\section{Disability \& Health Disparities}

Defining the term "disparity" is an enterprise marked with nearly as many approaches as defining "disability." Health disparity has been defined as broadly as population-specific differences in the presence of disease, health outcomes, or access to health care (HRSA, 2000), and as restrictively as differences in the quality of healthcare that are not due to accessrelated factors or clinical needs, preferences, and appropriateness of intervention (Smedley, Stith,
\& Nelson, 2002). For the purposes of this article, health disparities are defined as populationspecific differences in health indicators between people with disabilities and those without disabilities.

The need for ongoing surveillance of health and disability has been recognized in Healthy People 2010 with its call to add standardized disability identifiers to national surveillance instruments (Objective 6.1). Even with the irregular or limited number of large-scale population based data, information from a number of reports consistently document that people with disabilities, as a group, experience worse health than the general population. People with a variety of physical and cognitive disabilities are also more likely to experience early deaths, chronic conditions, and potentially preventable secondary conditions (Campbell et al., 1999; Lennox, Beange, \& Edwards, 2000; Turk, Scandale, Rosenbaum, \& Weber, 2001; USDHHS, 2001). People with disabilities have some of the highest rates of oral disease (NIDCR, 2002) and higher rates of diabetes than the general population (McDermott \& Platt, 2004). Adults, adolescents, and children with mental retardation compared with other populations experience poorer health and more difficulty in finding, getting to, and paying for appropriate healthcare (USDHHS, 2002). These differences are underscored by disparities in other areas of wellness including lower rates of high school completion, higher unemployment, and fewer social activities (USDHHS, 2001).

\section{Health Care Disparities}

Access to quality medical care, when and as often as needed, is critical for maintaining good health and functioning, detecting and intervening early for potential health problems, and addressing acute health concerns. For people with disabilities who experience a "thinner margin of health” (Pitetti \& Campbell, 1991), access to primary health care is particularly important for maintaining good health and functioning. Yet people with disabilities report having more unmet health care needs (NOD/Harris, 2004) and receiving fewer services for routine health care and preventive services than the general population (Chan, 
Doctor, MacLehose, Lawson, Rosenblatt, Baldwin, 1999; Diab \& Johnson, 2004; Drum, 2003; Drum, Horner-Johnson, Krahn, \& Culley, 2002; Hagglund, Clark, Conforti, \& Shigaki, 1999; Iezzoni, McCarthy, Davis, \& Siebens, 2000; NOD/Harris, 2004). For example, data from the 1994 National Health Interview Survey Disability Supplement showed that working-age people with mobility limitations experienced far lower rates of health services such as blood pressure checks, cholesterol screening, mammography, and far lower rates of health behavior counseling around issues related to alcohol and substance abuse, diet and eating habits, regular physical exercise, and smoking cessation (Jones \& Beatty, 2002). More recent data from a national survey of adult primary care providers identified physician-reported differences in the care of patients with and without disabilities. Physicians provided decreased attention to a number of preventive care services (i.e., blood pressure, cholesterol, colorectal screens, mammograms) and less counseling on high-risk behaviors (i.e., smoking, exercise, stress) for their adult patients with physical disabilities (RRTC: Health and Wellness, 2003).

Two state-population database linkage studies demonstrate other dimensions of inequitable access to health care. Individuals with disabilityeligible Medicaid codes are slightly overrepresented in the cancer registry for smokingrelated cancers, and women with mobility and/or cognitive impairments are at increased risk of having their cancers detected at later stages (Austin, 2003). A second population data-base study documented that adults with disability Medicaid codes participated in publicly sponsored drug and alcohol treatment at only one-half the rate of other Medicaid subpopulations (Krahn, Deck, Gabriel, \& Bersani, 2004), despite other studies suggesting substance abuse rates that are equal to or higher than the general population (Hubbard, Everett, \& Khan, 1996; Moore, Greer, \& Li, 1994).

Health differences between people with and without disabilities appear unrelated to insurance coverage, since people with disabilities are as likely to have insurance as the general population (NOD/Harris, 2004). Rather they appear to be more systemic in terms of health care provider behaviors, clinic site and medical equipment inaccessibility, transportation difficulties, inaccessible fitness facilities, and availability and accessibility of health information for persons with disabilities (Cardinal \& Spaziani, 2003; Downs, Wile, Krahn, \& Turner, 2004; O'Day, Dautel \& Scheer, 2002).

\section{Communication Disparities}

The dearth of interpreters and health professionals trained in American Sign Language and the lack of assistive listening devices, TV decoders, and TTYs can create barriers for deaf and hard of hearing people in accessing healthcare and health promotion activities (Cardinal \& Spaziani, 2003; O'Day et al., 2002; USDHHS, 2001). For people with vision impairments, the lack of readable signs and resources in alternative print formats can make participating in clinical encounters and in the healthcare system (such as reading a prescription) difficult. People with mental retardation and cognitive impairments experience a great deal of communication difficulty in accessing effective healthcare, including the lack of accessible documents in easy to understand "plain language" (TuffreyWijne, 1997). According to the Surgeon General (USDHHS, 2002), these challenges are even more daunting for people with mental retardation from minority communities where services are not provided in their primary language or that follow their traditional cultural practices.

\section{Health Promotion and Disease Prevention Disparities}

The Surgeon General has stressed the importance of individual responsibility with regard to healthy behaviors and the importance of individuals with disabilities engaging in health-promoting activities to maintain wellness and prevent the occurrence of secondary conditions (USDHHS, 2002; 2005). People with disabilities are at higher risk of being overweight and obese, engaging in less physical activity, being sedentary, and using alcohol and tobacco (Patrick, 2002). The associations are well known 
between smoking and lung cancer, alcohol and other drug use and cardiovascular problems, hypertension and stroke, and being overweight and sedentary and experiencing diabetes and cardiovascular problems. Individuals with disabilities can take responsibility for a portion of their own health by becoming joint managers of their own rehabilitation program (Marge, 1994), engaging in healthy behaviors (such as maintaining a well balanced diet and engaging in a recommended program of physical exercise) and avoiding harmful behaviors such as tobacco use and substance abuse (Rimmer \& Braddock, 2002).

A number of factors may contribute to disparities in accessing disease prevention and health promotion programs. For example, the cost of participating in fitness programs, transportation difficulties, and lack of disabilityknowledgeable staff are major barriers to successful health promotion (Rimmer, Braunscweig, Hedman, \& Heller, 2002). Other important barriers to participating in health promotion programs may include the physical inaccessibility of health promotion facilities and equipment and a lack of information in accessible formats (Cardinal \& Spaziani, 2003).

\section{Conclusion- Responding to Disparities}

Eliminating health discrepancies in people with disabilities requires changes in access to medical care, improvements in the delivery of health promotion, increased prevention strategies implemented for secondary conditions, and removal of environmental barriers. Responding to these health disparities requires a comprehensive, multi-level approach that involves persons with disabilities, health care and other service providers, and policy makers. Available data indicate that having a disability puts one at substantially higher risk for experiencing poorer health status than the general population. Disparities appear related to both differences in access to medical care and to health promotion services. These disparities need to be addressed at the level of the person with the disability, the professionals who provide services, and importantly, the policies that impede or facilitate better access to medical care and health promotion. Four categories of policy change are recommended along with key examples of needed policy reform:

- Legal and Regulatory Reforms that enforce the ADA to address accessibility in conjunction with broader definitions of medical necessity to address habilitation needs, simplification of regulations to make maneuvering the health care system easier, tax incentives that support persons with disabilities in purchasing equipment or making home modifications to increase access to the community, and increased physical accessibility of medical and fitness facilities and equipment (e.g., mammography machines, athletic equipment).

- Health Plan Benefits that ensure access to needed specialty care, habilitative and rehabilitative services, care coordinated “defragmentation”, and coverage for prescription medications and durable medical equipment.

- Communication Enhancement that includes interpreter services for non-English speakers, sign language interpreters, health information materials in alternative formats (e.g., large print, electronic copies for screen readers), adequate time for medical care appointments, and use of "plain language" to promote comprehension by all, but particularly people with cognitive disabilities.

- Health Promotion Programs that include access to generic health promotion programs like smoking cessation, weight management, drug and alcohol treatment, complementary and alternative medicine, and accommodation of facilities and staff to allow equitable participation by people with disabilities.

With the changing demographics of America, the proportion of persons experiencing disabilities will increase. Public health has a significant role to play in addressing and ameliorating the health disparities experienced by people with disabilities. 


\section{References}

American Federation for the Blind. (n.d.). Key definitions of statistical terms. Retrieved July 19, 2004, from http://www.afb.org/Section.asp?DocumentID=1280

Americans with Disabilities Act of 1990 [ADA] (1990). 42. US code 12101-213. Washington, DC: GPO.

Austin, D. (2003). Disabilities are risk factors for late stage of poor prognosis cancers. In Rehabilitation Research \& Training Center: Health \& Wellness Consortium (Eds.), State of the science conference proceedings (pp. 52-55). Portland, OR: Oregon Health \& Science University.

Bickenbach, J. E., Chatterji, S., Badley, E. M., \& Ustun, T. B. (1999). Models of disablement, universalism and the international classification of impairments, disabilities and handicaps. Social Science and Medicine, 48, 1173-1187.

Campbell, M. L., Sheets, D., \& Strong, P. S. (1999). Secondary health conditions among middle-aged individuals with chronic physical disabilities: Implications for unmet needs for services. Assistive Technology, 11, 105-122.

Cardinal, B. J., \& Spaziani, M. D. (2003). ADA compliance and the accessibility of physical activity facilities in western Oregon. American Journal of Health Promotion, 17, 197-201.

Centers for Disease Control and Prevention [CDC]. (2004). Behavioral risk factor surveillance system. Retrieved August 29, 2005, from

http://apps.nccd.cdc.gov/brfss/page.asp?yr=2003\&state=US\&cat=DL\#DL

Centers for Disease Control and Prevention [CDC]. (2004). National health interview survey. Retrieved August 29, 2005, from http://www.cdc.gov/nchs/datawh/nchsdefs/disability.htm

Chan, L., Doctor, J. N., MacLehose, R. F., Lawson, H., Rosenblatt, R. A., Baldwin, L. M. (1999). Do Medicare patients with disabilities receive preventive services? A population-based study. Archives of Physical Medicine and Rehabilitation, 80, 642-646.

DeJong, G. (1994). Toward a research and training capacity in disability policy. Policy Studies Journal 22(1), 152-60.

Diab, M. E., \& Johnston, M. V. (2004). Relationships between level of disability and receipt of preventive health services. Archives of Physical Medicine and Rehabilitation, 85, 749-757.

Downs, A., Wile, N., Krahn, G., \& Turner, A. (2004). Wellness promotion in persons with disabilities: Physicians' personal behaviors, attitudes, and practices. Rehabilitation Psychology, 49, 303-308.

Drum, C. E. (1998). The social construction of personnel policy: Implications for people with disabilities. Journal of Disability Policy Studies, 9(1), 125-150.

Drum, C. E. (2003). Behavioral risk factor surveillance system project: Health status \& disability. In Rehabilitation Research \& Training Center: Health \& Wellness Consortium (Eds.), State of the science conference proceedings (pp. 67-72). Portland, OR: Oregon Health \& Science University.

Drum, C. E. (2004). An overview of disability models and approaches. In C. E. Drum, G. L. Krahn, B. Ritacco, \& A. Drake (Eds.), Disability and public health curriculum outline (pp. 4-16). Oregon Office on Disability and Health. Portland, OR: Oregon Health \& Science University.

Drum, C. E., Horner-Johnson, W., Krahn, G. L., \& Culley, C. (2002). Disparity, differences and inequality: Examining the health of people with disabilities. Presented at Association of University Centers for Excellence in Disabilities Annual Meeting, Bethesda, MD.

Hagglund, K. J., Clark, M., Conforti, K., \& Shigaki, C. L. (1999). Access to health care services among people with disabilities receiving Medicaid. Medicine, 96, 447-453.

Health Resources \& Services Administration [HRSA]. (2000). Eliminating health disparities in the United States. Washington, DC: Author.

Hubbard, J. R., Everett, A. S., \& Khan, M. A. (1996). Alcohol and drug abuse in patients with physical disabilities. American Journal of Drug and Alcohol Abuse, 22, 215-231.

Humphrey, J. C. (2000). Researching disability politics, or, some problems with the social model in practice. Disability and Society, 15, 63-85.

Iezzoni, L. I., McCarthy, E. P., Davis, R. B., \& Siebens, H. (2000). Mobility impairments and use of screening and preventive services. American Journal of Public Health, 90, 955-961.

Johnston, M. (1996). Models of disability. The Psychologist, May, 205-210. 
Jones, G. C., \& Beatty, P. W. (2002). Disparities in preventative service use among working-age adults with mobility limitation. Unpublished Work.

Kailes, J. I. (2004). Can disability, chronic conditions, health and wellness coexist? Position Paper, Chicago, Illinois, National Center on Physical Activity and Disability. Retrieved September 13, 2005, from http://www.ncpad.org/wellness/fact_sheet.php?sheet=106

Kinne, S., Patrick, D. L., \& Doyle, D. L. (2004). Prevalence of secondary conditions among people with disabilities. American Journal of Public Health, 94, 443-445.

Krahn, G. (2003). Changing concepts in health, wellness, and disability. In Rehabilitation Research \& Training Center: Health \& Wellness Consortium (Eds.), State of the science conference proceedings (pp. 6-19). Portland, OR: Oregon Health \& Science University.

Krahn, G., Deck, D., Gabriel, R., \& Bersani, H. (2000). Examining access and success of drug and alcohol treatment for persons with disabilities. Presented at Annual Meeting of the American Public Health Association, Boston, MA.

Lennox, N. G., Beange, H., \& Edwards, N. S. (2000). The health needs of people with intellectual disability. Medical Journal of Australia, 173, 328-330.

Llewellyn, A., \& Hogan, K. (2000). The use and abuse of models of disability. Disability and Society, 15, 157-165.

Lollar, D. (2001). Public health trends in disability. In G. Albrecht, K. Seelman, \& M. Bury (Eds.), Handbook of disability studies, first edition (pp. 754-777). Thousand Oaks, CA: Sage Publications.

Lollar, D. J. (2002). Public health and disability: Emerging opportunities. Public Health Report, 117(2), 131-136.

Marge, M. (1988). Health promotion for persons with disabilities: moving beyond rehabilitation. American Journal of Health Promotion, 2, 29-35.

Marge, M. (1994). Toward a state of well-being: Promoting healthy behaviors to prevent secondary conditions. Retrieved September 13, 2005, from http://www.cdc.gov/ncbddd/dh/Publications/Conferences/1994aSB CP/1994iHealthyBehavior.ht $\underline{\mathrm{m}}$

McDermott, S., \& Platt, T. (2004). The health of adults with disability in family practice-1990-2003. Presented at the Conference of the National Center on Birth Defects and Developmental Disabilities, Washington, DC.

McNeil, J. M. (2001). Americans with disabilities, household economic studies, current population reports (pp. 1-20, 70-73). Retrieved September 13, 2005, from http://www.census.gov/prod/ 2001pubs/p70-73.pdf

McGinnis, J. M., Williams-Russo, P., \& Knickman, J. R. (2002). The case for more active policy attention to health promotion. Health Affairs 21(2), 78-93.

Moore, D., Greer, B. G., \& Li, L. (1994). Alcohol and other substance use abuse among people with disabilities. Journal of Social Behavior and Personality, 9, 369-382.

National Institute of Dental and Craniofacial Research [NIDCR]. (2002). A plan to eliminate craniofacial, oral, and dental health disparities. Bethesda, MD: Author.

National Organization on Disability [NOD]/Harris. (2004). Detailed results from the 2004 N.O.D./Harris survey of Americans with disabilities. New York, NY: National Organization on Disability \& Harris Interactive, Inc.

Nosek, M. A. (1996). Wellness among women with physical disabilities. In D. M. Krotoski, M. A. Nosek, \& M. A. Turk (Eds.), Women with physical disabilities: Achieving and maintaining health and well-being, 1st ed. (pp. 17-34). Baltimore: Paul H. Brookes Publishing Company.

O'Day, B., Dautel, P., \& Scheer, J. (2002). Barriers to healthcare for people with mobility impairments. Managed Care Quarterly, 10, 41-51.

Patrick, D. L. (2002). Leading health indicators: physical activity, overweight and obesity, tobacco use, and access to care. Presented at The Healthy People 2010 National Forum, Atlanta, GA. 
Pitetti, K. H., \& Campbell, K. D. (1991). Mentally-retarded individuals - a population at risk. Medicine and Science in Sports and Exercise, 23, 586-593.

Pope, A. M., and Tarlov, A. R. (1991). Disability in America: Toward a national agenda for prevention. Washington, D.C: National Academy Press.

Rehabilitation Research \& Training Center [RRTC]: Health \& Wellness Consortium. (2003). Summary of studies and key findings. Portland, OR: Oregon Health \& Science University.

Rimmer, J. H., \& Braddock, D. (2002). Health promotion for people with physical, cognitive and sensory disabilities: An emerging national priority. American Journal of Health Promotion, 16, 220-224.

Rimmer, J. H., Braunscweig, C., Hedman, G., and Heller, T. (2002). Center on Health Promotion Research for Persons with Disabilities: Final report. Chicago, IL: National Center on Physical Activity and Disability.

Rioux, M. H. (1999). When myths masquerade as science: Disability research from an equality-rights perspective. In L. Barton \& M. Oliver (Eds.), Disability studies: Past, present, and future. (Chapter 7, pp. 1-13) Leeds, England: The Disability Press.

Seekins, T., Clay, J., \& Ravesloot, C. (1994). A descriptive study of secondary conditions reported by a population of adults with physical disabilities served by 3 independent living centers in a rural state. Journal of Rehabilitation, 60, 47-51.

Simeonsson, R. J., \& Leskinen, M. (1999). Disability, secondary conditions and quality of life: conceptual issues. In R. J. Simeonsson \& L. N. McDevitt (Eds.), Issues in disability \& health: The role of secondary conditions \& quality of life (pp. 51-72). Chapel Hill, NC: University of North Carolina.

Smedley, B. D., \& Syme, L. S. (2000). Promoting health: intervention strategies from social and behavioral research. Washington, DC: National Academy Press.

Smedley, B. D., Stith, A. Y., and Nelson, A. R. (2002). Unequal treatment: Confronting racial and ethnic disparities in health care. Washington, D.C: National Academy Press.

Tuffrey-Wijne, I. (1997). Palliative care and learning disabilities. Nursing Times 93(31), 50-1.

Turk, M. A. (2004). Disability specific health secondary conditions: 10 years later. Presented at the Conference of the National Center on Birth Defects and Developmental Disabilities, Washington, DC.

Turk, M. A., Scandale, J., Rosenbaum, P. F., \& Weber, R. (2001). The health of women with cerebral palsy. Physical Medicine Rehabilitation Clinical North America, 12, 153-168.

U. S. Census Bureau [USCB]. (2004). Survey of income and program participation. Retrieved August 29, 2005, from http://www.census.gov/hhes/www/disability/disab_defn.html\#SIPP

U. S. Census Bureau [USCB]. (2005). American community survey. Retrieved August 29, 2005, from http://www.census.gov/acs/www/

U. S. Department of Health and Human Services [USDHHS]. (1993). Research plan for the National Center for Medical Rehabilitation Research. NIH Publication No. 93-3509. Washington, DC.

U. S. Department of Health and Human Services [USDHHS]. (2001). Healthy people 2010. Washington, DC: Office of Disease Prevention and Health Promotion.

U. S. Department of Health and Human Services [USDHHS]. (2002). Closing the gap: A national blueprint to improve the health of persons with mental retardation. Report of the Surgeon General's Conference on Health Disparities and Mental Retardation. Washington, D.C.: Author.

U. S. Department of Health and Human Services [USDHHS]. (2005). The surgeon general's call to action to improve the health and wellness of persons with disabilities. Atlanta, GA. Author.

Wilber, N., Mitra, M., Walker, D. K., Allen, D., Meyers, A. R., \& Tupper, P. (2003). Disability as a public health issue: Findings and reflections from the Massachusetts survey of secondary conditions. Milbank Quarterly, 80, 393-421.

World Health Organization. (1980). International classification of impairments, disabilities, and handicaps: A manual of classification relating to the consequences of disease. Geneva: Author.

World Health Organization. (2001). International classification of functioning, disability and health: ICF (pp. 3-25). Geneva: Author. 


\title{
Acknowledgements
}

This article was supported by the U.S. Department of Education, National Institute on Disability and Rehabilitation Research (NIDRR), Grant No. H133B990019. The information contained in this document is solely attributable to the authors and does not reflect the views or opinions of NIDRR.

\author{
Author Information \\ Charles E. Drum, JD, PhD \\ Oregon Health \& Science University \\ P.O. Box 574 \\ Portland, OR 97207 \\ Ph. 503-494-8047 \\ E-Mail: drumc@ohsu.edu \\ Gloria Krahn, $\mathrm{PhD}$, MPH \\ Carla Culley, MPH \\ Laura Hammond, MPH \\ Oregon Health \& Science University \\ * corresponding author
}

